SOCIAL RESEARCH REPORTS

ISSN: 2066-6861 (print), ISSN: 2067-5941 (electronic)

\title{
SEEING A MEDICAL DOCTOR IS ASSOCIATED WITH SERIOUSLY CONSIDERING QUITTING SMOKING
}

Anca D. DRAGOMIR, Wenxuan YANG, George LUTA

Social Research Reports, 2019, Vol. 11, Issue 3, pp. 9-17

The online version of this article can be found at:

www. researchreports.ro

\section{https://doi.org/10.33788/srr11.3.1}

Published by:

Expert Projects Publishing House

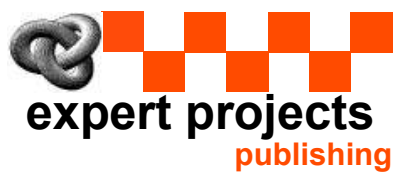

Covered by Index Copernicus International www.indexcopernicus.com

Directory of Open Access Journals

www.doaj.org

On behalf of:

Center for Program and Social Development

Aditional services and information about Social Research Reports can be found at:

www.researchreports.ro 


\title{
SEEING A MEDICAL DOCTOR IS ASSOCIATED WITH SERIOUSLY CONSIDERING QUITTING SMOKING
}

\author{
Anca D. DRAGOMIR ${ }^{1}$, Wenxuan YANG ${ }^{2}$, George LUTA ${ }^{3}$
}

\begin{abstract}
Smoking is a very significant public health problem. Quitting smoking will greatly reduce related morbidity and mortality. The purpose of this study was to examine the association between seeing a medical doctor during the past 12 months and seriously considering quitting smoking within the next 6 months, among US smokers. The self-reported information on 3102 current smokers used for the study was from the May 2010 Longitudinal Cohort from the Tobacco Use Supplement to the Current Population Survey. We used logistic regression models with generalized estimating equations (GEE) to account for the clustering of smokers within households. In unadjusted analysis, seeing a medical doctor in the past year was statistically significantly associated with seriously considering quitting smoking $(\mathrm{OR}=1.56,95 \% \mathrm{CI}$ : 1.33-1.82). The results after adjustment for confounders, and also after further adjustment for additional variables, were similar (OR=1.60, 95\% CI: 1.35-1.89). We found that seeing a medical doctor was statistically significantly associated with seriously considering quitting smoking among US smokers. Further research work should consider the potential role of income and marital status as effect modifiers for this association.
\end{abstract}

Keywords: smoking, quitting, self-reported, medical doctor, logistic regression.

\footnotetext{
${ }^{1}$ Georgetown University, Department of Oncology, Washington, DC, USA, E-mail: anca. dragomir@georgetown.edu

${ }^{2}$ Georgetown University, Department of Biostatistics, Bioinformatics and Biomathematics, Washington, DC, USA. E-mail: wy96@georgetown.edu

3 Georgetown University, Department of Biostatistics, Bioinformatics and Biomathematics, Washington, DC, USA. E-mail: george.luta@georgetown.edu
} 


\section{Introduction}

Smoking and the use of other tobacco products, including cigars and smokeless tobacco, causes or worsens numerous diseases and conditions. Some products also expose nearby people to toxic secondhand smoke. Smoking generally has negative health effects, because smoke inhalation inherently poses challenges to various physiologic processes such as respiration. A 2007 report states that each year, about 4.9 million people worldwide die because of smoking (West and Shiffman, 2007).

Smoking is one of the most common forms of recreational drug use. Tobacco smoking is the most popular form, being practiced by over one billion people globally, of whom the majority are in the developing world (WHO, 2014). Less common drugs for smoking include cannabis and opium. Cigarettes are primarily industrially manufactured but also can be hand-rolled from loose tobacco and rolling paper. Other smoking products include pipes, cigars, bidis, hookahs, vaporizers, and bongs.

Quitting smoking is beneficial for people's health, the sooner you quit the more you can reduce the chance of getting cancer and other diseases. The carbon monoxide level in blood drops to normal after 12 hours of quitting. The excess risk of coronary heart disease is half that of someone who still smokes, and the risk of a heart attack drops dramatically. The risk of cancers of the mouth, throat, esophagus, and bladder is cut in half. The risk of cervical cancer falls to that of a nonsmoker. The risk of stroke can fall to that of a nonsmoker after 2 to 5 years, and the risk of dying from lung cancer is about half that of a person who is still smoking (Office of the Surgeon General, 1989; World Health Organization, 2007).

We are not aware of any research studies to date that have analyzed the association between quitting smoking and seeing a medical doctor. We describe the results of two related studies. A cross-sectional study in Turkey indicated that smoking cessation practice by physicians for hospitalized patients in a tertiary hospital was associated with the patient's gender, education and morbidity (Baltaci et al., 2016). A cross-sectional study in Argentina involving a self-administered online survey found that recent medical graduates had better knowledge about cessation and were more likely to agree with a full smoking ban in recreational venues (Salgado, Mejía, Kaplan, and Pérez-Stable, 2017). In our study, we investigated the attitude of quitting smoking among current US smokers aged 18 old and older after seeing a medical doctor in the previous year.

\section{Methodology}

\section{Study population}

The data used in this study is from the May 2010 Longitudinal Cohort from the Tobacco Use Supplement to the Current Population Survey, conducted by the Census Bureau for the Bureau of Labor Statistics. The participants are 3102 current smokers aged 18 years old and older from the civilian non-institutional population 
of the US, who completed the labor force interview from the May 2010 cohort. All the information collected from these participants was self-reported.

\section{Outcome variable}

The outcome variable is seriously considering quitting smoking and it is based on the question: "Are you seriously considering quitting smoking within the next 6 months (yes/no)?"

\section{Main predictor variable}

The main predictor variable was being seen by a medical doctor during the previous year.

\section{Other variables}

The demographic characteristics were collected for each participant and were categorized as follows: age (18-24,25-44, 45-64, and >64 years old), education ( $<$ high school, high school, and college or more), marital status (married, divorce/ widowed/separated, and never married), race/ethnicity (white, black, and others), sex, work status (employed, unemployed, and not in the labor force), and income $(<\$ 5000, \$ 5000-\$ 50000, \$ 50000-\$ 100000$, and $>\$ 10000)$. We also used in the statistical analysis the variable being seen by a dentist during the previous year. All variables were used as categorical in the logistic regression models.

\section{Statistical analysis}

A preliminary analysis was performed for the whole sample of 3012 current smokers. Descriptive statistics, including frequencies and proportions, were calculated for all categorical variables. Logistic regression models with generalized estimating equations (GEE) were used to evaluate the associations between seeing a medical doctor and seriously considering quitting smoking, controlling for confounders. GEE (Liang \& Zeger, 1986) were used to account for the clustering of binary outcomes of current smokers within the same household. The logistic regression models were used with an exchangeable working correlation structure. There are 2757 households selected in this research, so the number of clusters (households) is 2757, and there are up to five smokers in each cluster (household). Logistic regression models with GEE that included only one variable were used to identify the confounders. Eight models had quitting as the binary outcome, while other eight models had seeing a doctor as the binary outcome. Variables which had significant associations $(\mathrm{p}<0.05)$ with both having seen a doctor and seriously considering quitting smoking were considered as confounders. Estimated odds ratios, $95 \%$ confidence intervals based on empirical (robust) standard errors, and p-values were reported from related statistical tests. All statistical analyses were completed using SAS 9.4 (SAS Institute Inc. Cary, NC). 


\section{Results}

\section{Preliminary analysis}

The participants were 3102 current smokers aged 18 years old and older from the civilian non-institutional population of the US. All information was collected via a detailed questionnaire. The frequencies and proportions were listed in Table 1 below to present the descriptive statistics for the study variables.

Table 1. Descriptive Statistics for the Study Variables.

\begin{tabular}{|c|c|c|c|}
\hline Variables & & Frequency & Proportion \\
\hline \multirow[t]{2}{*}{ Intent to quit } & Yes & 1314 & $42.4 \%$ \\
\hline & No & 1788 & $57.6 \%$ \\
\hline \multirow{2}{*}{$\begin{array}{l}\text { Have seen a } \\
\text { Doctor }\end{array}$} & Yes & 2081 & $67.1 \%$ \\
\hline & No & 1021 & $32.9 \%$ \\
\hline \multirow[t]{2}{*}{ Sex } & Male & 1530 & $49.3 \%$ \\
\hline & Female & 1572 & $50.7 \%$ \\
\hline \multirow[t]{3}{*}{ Education } & Less than high school & 503 & $16.2 \%$ \\
\hline & High school & 2493 & $80.4 \%$ \\
\hline & College or more & 106 & $3.4 \%$ \\
\hline \multirow[t]{4}{*}{ Income } & Less than $\$ 5000$ & 93 & $3.0 \%$ \\
\hline & $\$ 5000-\$ 50000$ & 1836 & $59.2 \%$ \\
\hline & $\$ 50000-\$ 100000$ & 891 & $28.7 \%$ \\
\hline & Large than $\$ 100000$ & 282 & $9.1 \%$ \\
\hline \multirow[t]{4}{*}{ Age group } & $18-24$ & 151 & $4.88 \%$ \\
\hline & $25-44$ & 1109 & $35.8 \%$ \\
\hline & $45-64$ & 1508 & $48.6 \%$ \\
\hline & $>64$ & 334 & $10.8 \%$ \\
\hline \multirow[t]{3}{*}{ Work status } & Employed & 1890 & $60.9 \%$ \\
\hline & Unemployed & 288 & $9.3 \%$ \\
\hline & Not in the labor force & 924 & $29.8 \%$ \\
\hline \multirow[t]{3}{*}{ Marital status } & Married & 1351 & $43.6 \%$ \\
\hline & Windowed or divorced & 1003 & $32.3 \%$ \\
\hline & Never married & 748 & $24.1 \%$ \\
\hline \multirow[t]{4}{*}{ Race } & White & 2640 & $85.5 \%$ \\
\hline & Black & 289 & $9.3 \%$ \\
\hline & Others & 159 & $5.2 \%$ \\
\hline & Missing & 14 & \\
\hline \multirow{3}{*}{$\begin{array}{l}\text { Have seen a } \\
\text { dentist }\end{array}$} & Yes & 1338 & $43.2 \%$ \\
\hline & No & 1758 & $56.8 \%$ \\
\hline & Missing & 6 & \\
\hline
\end{tabular}


Regarding the outcome variable of seriously considering quitting smoking in the next six month, $42.4 \%$ smokers were considering to quit while other $57.6 \%$ were not. Most smokers (67.1\%) have seen a doctor in the previous twelve months. About $80 \%$ of current smokers had high school degrees and $85.5 \%$ of the current smokers in this research were white.

Table 2. The Associations with Seriously Considering Quitting Smoking within 6 Months

\begin{tabular}{|c|c|c|c|c|}
\hline Variable & & Odds ratio & $95 \% \mathrm{Cl}$ & $P$ value \\
\hline \multirow[t]{3}{*}{ Education } & Less than high school & 1 & & \\
\hline & High school & 1.46 & $(1.20,1.79)$ & $<.001$ \\
\hline & College or more & 1.20 & $(0.78,1.84)$ & 0.403 \\
\hline \multirow[t]{4}{*}{ Age group } & $18-24$ & 1 & & \\
\hline & $25-44$ & 1.07 & $(0.77,1.53)$ & 0.689 \\
\hline & $45-64$ & 0.87 & $(0.61,1.23)$ & 0.429 \\
\hline & $>64$ & 0.58 & $(0.39,0.87)$ & 0.008 \\
\hline \multirow[t]{3}{*}{ Work status } & Employed & 1 & & \\
\hline & Unemployed & 1.07 & $(0.84,1.38)$ & 0.571 \\
\hline & Not in the labor force & 0.84 & $(0.71,0.98)$ & 0.030 \\
\hline \multirow{2}{*}{$\begin{array}{l}\text { Have seen a } \\
\text { dentist }\end{array}$} & Yes & 1 & & \\
\hline & No & 0.77 & $(0.66,0.89)$ & $<.001$ \\
\hline \multirow[t]{2}{*}{ Sex } & Male & 1 & & \\
\hline & Female & 1.07 & $(0.93,1.23)$ & 0.323 \\
\hline \multirow[t]{3}{*}{ Race } & White & 1 & & \\
\hline & Black & 1.19 & $(0.93,1.52)$ & 0.168 \\
\hline & others & 0.87 & $(0.63,1.21)$ & 0.420 \\
\hline \multirow[t]{4}{*}{ Income } & Less than $\$ 5000$ & 1 & & \\
\hline & $\$ 5000-\$ 50000$ & 0.99 & $(0.64,1.52)$ & 0.967 \\
\hline & $\$ 50000-\$ 100000$ & 1.07 & $(0.69,1.67)$ & 0.752 \\
\hline & Large than $\$ 100000$ & 1.26 & $(0.78,2.06)$ & 0.346 \\
\hline \multirow{3}{*}{$\begin{array}{l}\text { Marital } \\
\text { status }\end{array}$} & Married & 1 & & \\
\hline & Windowed or divorced & 0.86 & $(0.73,1.02)$ & 0.092 \\
\hline & Never married & 1.03 & $(0.86,1.23)$ & 0.742 \\
\hline
\end{tabular}

Table 2 shows the associations of the variables with seriously considering quitting smoking within 6 months. Education level, age group, work status and seeing a dentist were associated with seriously considering quitting smoking. 
Table 3. The Associations with Seeing a Medical Doctor during the Previous Year

\begin{tabular}{|c|c|c|c|c|}
\hline Variable & & Odds ratio & $95 \% \mathrm{Cl}$ & $P$ value \\
\hline \multirow[t]{3}{*}{ Education } & $\begin{array}{l}\text { Less than high } \\
\text { school }\end{array}$ & 1 & & \\
\hline & High school & 1.47 & $(1.20,1.78)$ & $<.001$ \\
\hline & College or more & 2.41 & $(1.48,3.92)$ & $<.001$ \\
\hline \multirow[t]{4}{*}{ Age group } & $18-24$ & 1 & & \\
\hline & $25-44$ & 1.54 & $(1.09,2.18)$ & 0.016 \\
\hline & $45-64$ & 2.35 & $(1.66,3.32)$ & $<.001$ \\
\hline & $>64$ & 3.88 & $(2.54,5.93)$ & $<.001$ \\
\hline \multirow[t]{3}{*}{ Work status } & Employed & 1 & & \\
\hline & Unemployed & 0.68 & $(0.52,0.87)$ & 0.003 \\
\hline & $\begin{array}{l}\text { Not in the labor } \\
\text { force }\end{array}$ & 1.63 & $(1.37,1.95)$ & $<.001$ \\
\hline \multirow{2}{*}{$\begin{array}{l}\text { Have seen a } \\
\text { dentist }\end{array}$} & Yes & 1 & & \\
\hline & No & 0.28 & $(0.23,033)$ & $<.001$ \\
\hline \multirow[t]{2}{*}{ Sex } & Male & 1 & & \\
\hline & Female & 2.04 & $(1.76,2.36)$ & $<.001$ \\
\hline \multirow[t]{3}{*}{ Race } & White & 1 & & \\
\hline & Black & 1.07 & $(0.82,1.40)$ & 0.608 \\
\hline & others & 0.81 & $(0.58,1.13)$ & 0.219 \\
\hline \multirow[t]{4}{*}{ Income } & Less than $\$ 5000$ & 1 & & \\
\hline & $\$ 5000-\$ 50000$ & 0.92 & $(0.59,1.45)$ & 0.733 \\
\hline & $\$ 50000-\$ 100000$ & 1.09 & $(0.69,1.73)$ & 0.717 \\
\hline & Large than $\$ 100000$ & 1.27 & $(0.76,2.13)$ & 0.357 \\
\hline \multirow[t]{3}{*}{ Marital } & Married & 1 & & \\
\hline & $\begin{array}{l}\text { Windowed or di- } \\
\text { vorced }\end{array}$ & 1.01 & $(0.85,1.22)$ & 0.878 \\
\hline & Never married & 0.55 & $(0.45,0.66)$ & $<.001$ \\
\hline
\end{tabular}

Table 3 shows the associations of the variables with seeing a medical doctor in the previous year. Education level, age group, work status, sex, marital status and seeing a dentist were associated with seriously considering quitting smoking.

The variables significantly associated $(\mathrm{p}<0.005)$ with both seriously consider quitting smoking and having seen a medical doctor, specifically age group, education level, work status, and seeing a dentist, were considered as confounders; they were included to be adjusted for in the primary model. 
Table 4. The Association between Seeing a Medical Doctor and Seriously Considering Quitting Smoking

\begin{tabular}{|l|l|l|l|}
\hline Model & Odds ratio & $95 \% \mathrm{Cl}$ & P value \\
\hline Unadjusted model & 1.56 & $(1.33,1.82)$ & $<0.001$ \\
\hline Adjusted model $1^{*}$ & 1.60 & $(1.35,1.89)$ & $<0.001$ \\
\hline Adjusted model $2^{\#}$ & 1.60 & $(1.35,1.89)$ & $<0.001$ \\
\hline
\end{tabular}

"Model included adjustment for education level, age group, work status, and seeing a dentist. \#Model included adjustment for all variables.

Three logistic regression models with GEE were considered to evaluate the association between seeing a medical doctor and seriously considering quitting smoking. The first logistic regression model with GEE included having seen a medical doctor as the only variable, to provide results regarding the unadjusted association. The odds of seriously considering quitting smoking for current smokers who have seen a doctor in the previous year were 1.56 times higher than the odds of seriously considering quitting smoking for current smokers who haven't seen a doctor. The $95 \%$ confidence interval was $(1.33,1.82)$, which excluded 1 , and $\mathrm{p}<0.001$, both indicating that the results were statistically significant.

The second logistic regression model with GEE involved adjustment for age group, education level, work status and seeing a dentist. The odds of seriously considering quitting smoking for current smokers who have seen a doctor in the previous year were 1.60 times higher than the odds of seriously considering quitting smoking for current smokers who haven't seen a doctor, after controlling for age group, education level, work status and seeing a dentist. The $95 \%$ confidence interval was $(1.35,1.89)$, which excluded 1 , and $\mathrm{p}<0.001$, both indicating that the results were statistically significant.

The corresponding results from a the logistic regression model with GEE that included all study variables were unchanged ( $\mathrm{OR}=1.60,95 \% \mathrm{CI}: 1.35-1.89)$, with $\mathrm{p}<0.001$, which shows a statistically significant association between seeing a medical doctor and seriously considering quitting smoking, after adjustment for all the other variables. 


\section{Discussion and Conclusions}

The goal of this exploratory study was to determine whether seeing a medical doctor in the previous year was associated with seriously considering quitting smoking in the next six months among current US smokers. By using logistic regression models with GEE to account for the potential correlation of the intent to quit outcomes for smokers from the same household, our study found that seeing a medical doctor was statistically significantly associated with seriously considering quitting smoking ( $\mathrm{OR}=1.56,95 \% \mathrm{CI}$ : 1.33-1.82). Age group, education level, work status and seeing a dentist, which were associated with both seeing a medical doctor and seriously considering quitting, were considered as confounders and were adjusted for using a logistic regression model with GEE. The adjusted results were similar to the unadjusted results and indicated that seeing a medical doctor was significantly associated with seriously considering quitting smoking $(\mathrm{OR}=1.60$, 95\% CI: 1.35-1.89). The corresponding results from a logistic regression model with GEE that included adjustment for additional variables were unchanged $(\mathrm{OR}=1.60,95 \%$ CI: $1.35-1.89)$.

The interpretation of the findings of the current study should be considered within the context of the study limitations. This study used self-reported, crosssectional data, which makes it prone to report bias and limits the ability to establish cause-effect relationships. While our analyses controlled for several important predictors of intention to quit including age, race, education level and income, it is possible that there might be residual confounding related to other variables such as anxiety, alcohol use and financial stress. Such confounding would weaken the ability of the study to provide results that may be given a causal interpretation. Since we do not know what were the specific reasons for the participants to see a medical doctor during the previous year, how many visits each participant had, and if the medical doctor has advised the participants to quit smoking during those visits or not, we cannot further clarify the specific mechanism underlying the association under investigation. Future statistical analyses should evaluate the potential role of income and marital status as potential effect modifiers for the association of interest, and also the potential impact on the results of using different categorizations for the age groups and education levels. Further studies should use longitudinal data to evaluate the proportion of successful smoking cessation among the current smokers who are seriously considering quitting smoking in the near future. 


\section{References}

Baltaci, D., Aydin, L.Y., Alasan, F., Deler, M.H., Karacam, M.S., Turker, Y., Gur, M., \& Sariguzel, F.(2016). Evaluation of smoking cessation practice by physicians for hospitalized patients in a tertiary hospital. Journal of the Pakistan Medical Association, 66, 1547-1553.

Liang, K-Y., \& Zeger, S.L. (1986). Longitudinal Data Analysis Using Generalized Linear Models, Biometrika, 73, 13-22.

Salgado, M.V., Mejía, R.M., Kaplan, C.P., \& Pérez-Stable, E.J. (2017). Smoking-Related Attitudes and Knowledge Among Medical Students and Recent Graduates in Argentina: A Cross-Sectional Study. Journal of General Internal Medicine, 32, 549-555.

US Public Health Service, Office of the Surgeon General (1989). Reducing the health consequences of smoking: 25 years of progress. A report of the Surgeon General, US Department of Health and Human Services, Atlanta, USA.

West, R., \& Shiffman, S. (2007). Fast Facts: Smoking Cessation, (2nd ed.), Health Press Ltd., Abingdon, England.

World Health Organization (2007). Tobacco Control: Reversal of Risk after Quitting Smoking, Vol. 11 in the series IARC Handbooks of Cancer Prevention, IARC Press, Lyon, France.

World Health Organization (2014). Tobacco. Fact sheet N 339, Retrieved 13 May 2015. 